\title{
Tricellulin is regulated via interleukin-13-receptor $\alpha 2$, affects macromolecule uptake, and is decreased in ulcerative colitis
}

\author{
SM Krug ${ }^{1}$, C Bojarski ${ }^{2}$, A Fromm ${ }^{1}$, IM Lee ${ }^{1}$, P Dames $^{1}$, JF Richter ${ }^{3}$, JR Turner ${ }^{4}$, M Fromm ${ }^{1,5}$ and \\ J-D Schulzke ${ }^{1,5}$
}

In the two inflammatory bowel diseases, ulcerative colitis (UC) and Crohn's disease (CD), altered expression of tight junction (TJ) proteins leads to an impaired epithelial barrier including increased uptake of luminal antigens supporting the inflammation. Here, we focused on regulation of tricellulin (Tric), a protein of the tricellular TJ essential for the barrier against macromolecules, and hypothesized a role in paracellular antigen uptake. We report that Tric is downregulated in $\mathrm{UC}$, but not in CD, and that its reduction increases the passage of macromolecules. Using a novel visualization method, passage sites were identified at TJ regions usually sealed by Tric. We show that interleukin-13 (IL-13), beyond its known effect on claudin-2, downregulates Tric expression. These two effects of IL-13 are regulated by different signaling pathways: The IL-13 receptor $\alpha 1$ upregulates claudin-2, whereas IL-13 receptor $\alpha 2$ downregulates Tric. We suggest to target the $\alpha 2$ receptor in future developments of therapeutical IL-13-based biologicals.

\section{INTRODUCTION}

The intestinal epithelium consists of a polarized single cell layer with a multi-protein complex, the tight junction (TJ), which strictly regulates paracellular passage of ions, molecules, and water. This regulation is determined by transmembrane proteins of the TJ comprising of four families: four-transmembrane TJ proteins include the family of claudins with 27 members in mammals, ${ }^{1}$ and the TJ-associated MARVEL proteins $^{2}$ containing occludin, ${ }^{3}$ MARVEL D $3,{ }^{2,4}$ and tricellulin (Tric). ${ }^{5}$ Most of the claudins form barriers but some form paracellular ion and water channels. ${ }^{6,7}$ Junctional adhesion molecules $^{8}$ and the most recently described group of angulins ${ }^{9}$ span the membrane once. Angulins and Tric are located at the tricellular TJ (tTJ), the region where three or more cells meet and their bTJ (bicellular TJ) converge laterally forming a central tube. We have previously shown that Tric has an important role in sealing the tTJ, particularly to macromolecules. ${ }^{10,11}$

Integrity of the epithelial barrier is impaired in a variety of pathological conditions, for example, in the inflammatory bowel diseases (IBD) Crohn's disease (CD) ${ }^{12}$ and ulcerative colitis (UC). ${ }^{13}$ Although pathogenesis of the barrier defect in IBDs is still unclear, ${ }^{14}$ several studies demonstrate that proinflammatory cytokines including tumor necrosis factor $\alpha,{ }^{15}$ interferon $\gamma^{16,17}$ and interleukin-13 (IL-13) ${ }^{18,19}$ alter barrier function by changing TJ protein function and expression. For example, IL-13 has been linked as proinflammatory cytokine to UC, stimulating epithelial cell apoptosis and enhancing barrier defects, predominantly by upregulation of the cation-selective paracellular channel claudin-2. ${ }^{18-20}$

IL-13 is a cytokine which is released by Th2 cells sharing biological properties with IL-4 and both cytokines are involved in immune-mediated processes, where they often act in a manner that opposes Th1-polarized inflammation. ${ }^{21}$ Not only in UC but also in asthma IL-13 and IL-4 have been reported to work synergistically to enhance inflammatory activity. Two IL-13 receptor complexes are described and the balance between these is believed to regulate both quantitative and qualitative effects of IL-13 signaling. ${ }^{22-25}$ The first consists of a

${ }^{1}$ Institute of Clinical Physiology, Charité-Universitätsmedizin Berlin, Campus Benjamin Franklin, Berlin, Germany. ${ }^{2}$ Department of Gastroenterology, Rheumatology and Infectious Diseases, Charité — Universitätsmedizin, Campus Benjamin Franklin, Berlin, Germany. ${ }^{3}$ Institute for Anatomy II, Jena University Hospital, Jena, Germany and ${ }^{4}$ Departments of Pathology and Medicine (GI), Brigham and Women's Hospital and Harvard Medical School, Boston, USA. Correspondence: J-D Schulzke (joerg.schulzke@charite.de)

${ }^{5}$ These authors contributed equally to this work. 
receptor complex composed of the IL-4 receptor $\alpha$ (IL4R $\alpha$ ) and the IL-13 receptor $\alpha 1$ (IL13R $\alpha 1),{ }^{26,27}$ the second is generated by IL-13 receptor $\alpha 2$ (IL13R $\alpha 2)$.

For IL4R $\alpha /$ IL-13R $\alpha 1$ signaling, phosphorylation of STAT $1,{ }^{28}$ STAT6, ${ }^{29}$ and STAT3 ${ }^{28}$ have been reported as well as signaling via the MAPK and PI3K pathways ${ }^{30-32}$ and have been connected to claudin-2 upregulation by IL-13. ${ }^{33}$

Two variants of IL13R $\alpha 2$, which differ in activity, have been described, a soluble and a cell surface-bound. The soluble form found in urine and serum of mice ${ }^{34}$ is described as a decoy receptor that partially inhibits effects of IL-13; ${ }^{23,35}$ function of the human soluble form is more controversial. ${ }^{36,37}$ In contrast, the cell surface-bound form of IL13R $\alpha 2$ stimulates the transcription factor complex activator protein (AP-1), ${ }^{38,39}$ phosphorylates STAT3, ${ }^{40}$ and enhances MAPK, ${ }^{38} \mathrm{PI} 3 \mathrm{~K},{ }^{41}$ and ERK1/2 signaling, ${ }^{39}$ both in rodents and humans.

In this study, we analyzed the expression of the TJ protein Tric in IBD and found it to be downregulated in UC, but not $\mathrm{CD}$. We showed that this altered expression is driven by the UC key cytokine IL-13 via IL13R $\alpha 2$. Although IL-13 also upregulates claudin-2 expression, we found that the signaling mechanisms differed from those responsible for Tric downregulation. In contrast to increased water and cation flux after claudin-2 upregulation, we found that IL-13-induced suppression of Tric led to enhanced paracellular macromolecular uptake, which we were able to localize at tTJs. This may represent a novel mechanism for increased luminal uptake of antigens in UC.

\section{RESULTS}

When comparing membrane protein expression levels of Tric within sigmoid colon tissue of IBD and control (Ctrl) patients, it was conspicuous that there was profound and substantial reduction of Tric in UC, but not in CD patients (Figure 1a,d), comparable to changes reported for claudin-4 (Cldn-4) $)^{42,43}$ (Figure 1c,d). This finding is also in line with GEO expression data, reporting Tric (synonym: MARVEL D2) to be downregulated in inflamed UC tissue (GDS3119), ${ }^{44,45}$ but not in CD (GDS560). ${ }^{46}$ Claudin-2 (Cldn-2) nearly absent in Ctrl served as control for changes in $\operatorname{IBD}^{47}$ (Figure 1b,d). Impedance spectroscopic analysis of UC samples revealed that, although transepithelial resistance (TER) was similar to that of controls, epithelial resistance was decreased, whereas subepithelial resistance was increased due to inflammatory thickening of the subepithelium due to edema and condensed collagenous fibers (Figure 1e). Permeabilities for paracellular flux markers as fluorescein and $4 \mathrm{kDa}$-FITC-dextran (FD4) were increased indicating an impaired paracellular barrier (Figure 1f). Immunostainings of cryosections (Figure 2) revealed that in control patients, Tric was present all along the crypt and the surface epithelium, whereas Cldn-2 was only detectable in the depths of the crypts. In both IBD, Cldn-2 expression was increased and localization was extended to the total length of the crypts and to the surface epithelium. Tric was decreased in UC patients, whereas in CD patients a shift of localization seemed to occur. Although in the crypts the signal seemed to be slightly reduced, an increase of signals was observed in the surface epithelium, which also was extended from the apicolateral regions of the TJ to more basolateral regions. However, these changes in localization did not occur in all CD samples analyzed.

To investigate the origin of the UC-specific change in Tric expression, the intestinal epithelial cell line HT-29/B6 was treated with cytokines known to be involved in IBD (Supplementary Figure S1 online). IL-13, a major effector in UC, ${ }^{18}$ not only increased Cldn-2 but also decreased Tric expression (Figure 3a, Supplementary Figure S1). All other cytokines tested affected only Cldn-2 (Supplementary Figure S1). On mRNA level, Tric was reduced to $64 \pm 8 \%$ $\left.{ }^{* *} P<0.01, n=6\right)$ and Cldn-2 increased to $238 \pm 24 \%$ of controls $\left({ }^{* *} P<0.001, n=6\right)$. mRNA and protein half-lives were not affected, indicating that IL-13 did not affect protein or mRNA stability. At $100 \mathrm{ng} \mathrm{m}^{-1}$, IL-13 had no effect on epithelial apoptotic rate (Supplementary Table S1), measured by TUNEL staining and previously reported. ${ }^{48}$

IL-13 decreased TER by $62 \%$, whereas permeability for the macromolecule FD4 was increased from $0.06 \pm 0.01$ to $0.15 \pm 0.01 \times 10^{-6} \mathrm{~cm} \mathrm{~s}^{-1}$ (Figure 3b,c, $n=7,{ }^{* * *} P<0.001$ ). Comparable results were achieved when Tric was downregulated by stable transfection with specific shRNA (Figure 3d,e), namely increased permeability to FD4 $(n=11)$ and to $10 \mathrm{kDa}-\mathrm{FITC}$ dextran ( $n=4$; Figure 3f, Supplementary Figure S2). This provides direct evidence that the observed increase in macromolecule permeability, that is, the leak pathway, ${ }^{49}$ was based on the decrease Tric alone, not on alterations of cldn-2 or of occludin, as expression of both was unchanged (Figure 3d,e). Neither was the expression of angulins affected by Tric knockdown (Supplementary Figure S3). Together with this, a decrease in TER occurred (Vec: $1325 \pm 174 \Omega \mathrm{cm}^{2}$; shTRIC: $\left.730 \pm 64 \Omega \mathrm{cm}^{2} ;{ }^{\star} P<0.05, n=11\right)$ which, however, was lower as in the IL-13-treated cells because the TER-decreasing effect of Cldn-2 was lacking here.

To confirm the cell culture findings for IL-13 and Tric in colon epithelium, mice were treated with IL-13 and protein expression of Tric as well as functional consequences for the intestine were analyzed by electrophysiological experiments. The chosen dose and duration of the treatment did not lead to obvious changes in the intestinal architecture (Supplementary Figure S4A), but a decrease in epithelial resistance was observed indicating impairment of the mucosal barrier, whereas the subepithelial resistance was unaffected (Supplementary Figure S4B, $\left.{ }^{\star} P<0.05, n=5\right)$. Macromolecular permeability for FD4 was doubled in the colon of IL-13treated mice (Figure 4a, ${ }^{\star} P<0.05, n=8$ ). Also, the effect of IL-13 on expression and localization of Tric as well as of Cldn-2 was reproducible in mice (Figure $4 \mathbf{b}, \mathbf{c},{ }^{\star} P<0.05, n=7-9$; Supplementary Figure S4C).

To elucidate the signaling of IL-13 involved in Tric downregulation several approaches were tested in cell culture. Pretreatment of $1 \mathrm{~h}$ with inhibitory antibodies against the two IL-13 receptors was used to inhibit the interaction of IL-13 (Figure 5). Importantly, anti-IL13R $\alpha 1$ was able to block the 

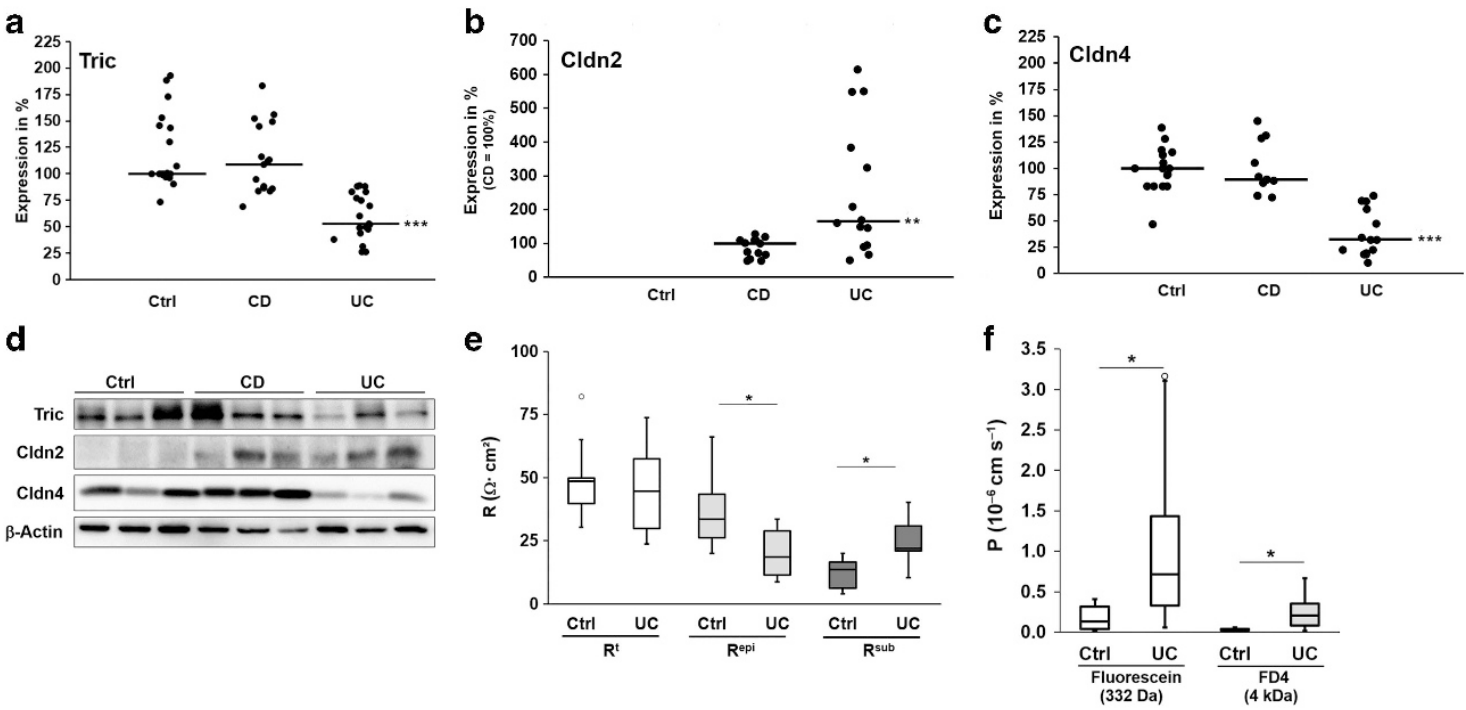

Figure 1 Expression, functional, and electrophysiological analysis of human biopsies. (a) Scatterplot of tricellulin protein expression in sigmoid colon biopsies of Ctrl, CD and UC. Median of Ctrl is set 100\%. Tricellulin is downregulated in UC, whereas in CD no difference to controls occurs (median; Ctrl: $100.0 \%, n=20$; CD: $108.6 \%, n=17$; UC: $53.0 \%, n=19,{ }^{* * *} P<0.001$ ). (b) Scatterplot of claudin-2 protein expression in sigmoid colon of Ctrl, CD, and UC. Because Ctrl patients show no claudin-2 expression, the median of CD is set $100 \%$. In both diseases claudin-2 is upregulated, however in UC this increase is higher than in $\mathrm{CD}\left({ }^{* *} \mathrm{P}<0.01\right)$. (c) Scatterplot of claudin-4 protein expression in sigmoid colon of Ctrl, CD, and UC. Median of Ctrl is set $100 \%$. Claudin-4 is downregulated in UC, whereas in CD no significant difference to Ctrl occurs (Ctrl: $100.0 \%, n=15 ; \mathrm{CD}: 89.4 \%, n=11 ; \mathrm{UC}: 32.3 \%, n=13$, $\left.{ }^{* * *} P<0.001\right)$. (d) Representative western blot images of sigmoid colon tissue of Ctrl, CD, and UC. (e) Electrical resistances of sigmoid colon of Ctrl and UC $(n=8)$. Although the epithelial resistance $\left(\mathrm{R}^{\mathrm{epi}}\right)$ is decreased in UC $\left({ }^{\star} P<0.05\right)$, the resistance of the subepithelial layers $\left(\mathrm{R}^{\mathrm{sub}}\right)$ is increased $\left({ }^{\star} P<0.05\right)$, resulting in an almost unchanged transepithelial resistance $\left(\mathrm{R}^{\mathrm{t}}\right)$. (f) Permeability for the paracellular flux markers fluorescein and $4 \mathrm{kDa}-\mathrm{FITC}$ dextran. Both permeabilities are increased in UC (fluorescein: Ctrl: $0.18 \pm 0.07 \times 10^{-6} \mathrm{~cm} \mathrm{~s}^{-1}, n=6, \mathrm{UC}: 1.07 \pm 0.41 \times 10^{-6} \mathrm{~cm} \mathrm{~s}^{-1}, n=7,{ }^{\star} P<0.05 ; \mathrm{FD} 4$ : Ctrl: $0.03 \pm 0.01 \times 10^{-6} \mathrm{~cm} \mathrm{~s}^{-1}, n=6$, UC: $\left.0.26 \pm 0.10 \times 10^{-6} \mathrm{~cm} \mathrm{~s}^{-1}, n=6,{ }^{\star} P<0.05\right)$.
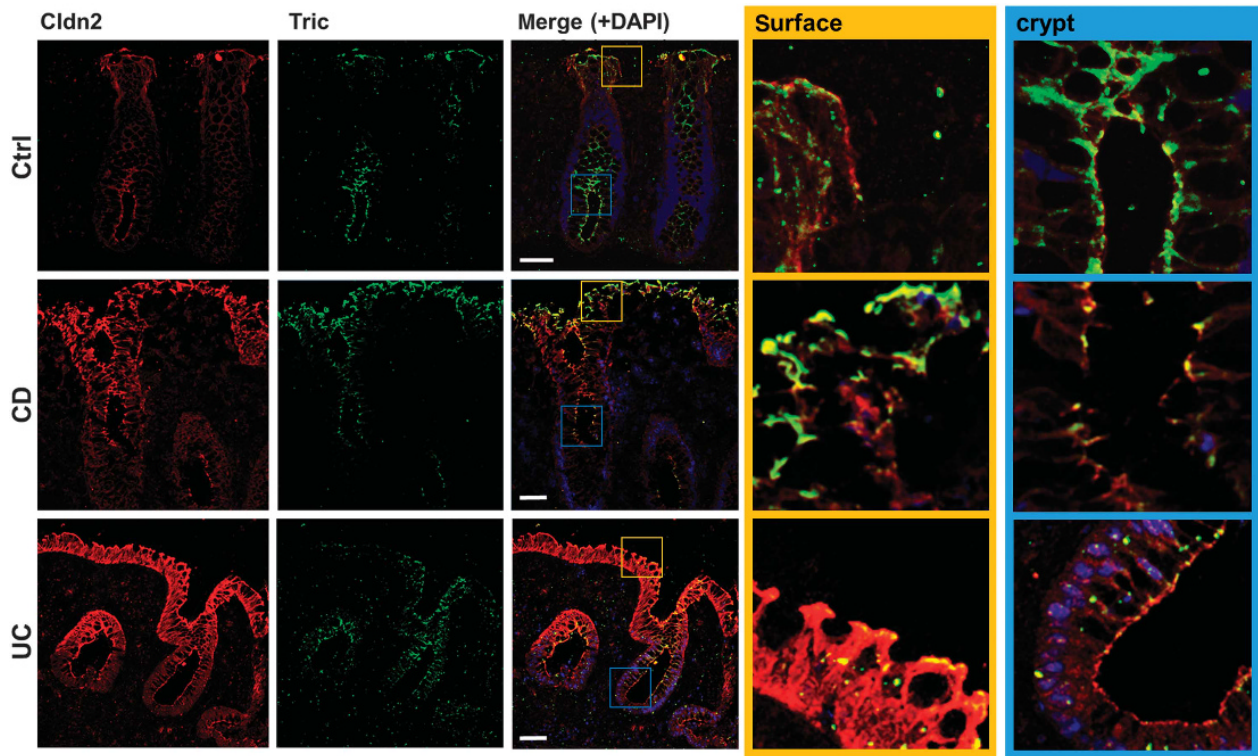

Figure 2 Localization of claudin-2 (red) and tricellulin (green) in human colon biopsies. Representative immunofluorescent stainings of cryosections of patient biopsies. Although claudin-2 is only expressed within the crypts of control patients (ctrl), it is expressed all along the crypt and surface in CD and UC patients. Tricellulin is present in all areas of the crypt and is also detectable in surface areas of the control patients. In UC, a decreased expression is observed, whereas in CD patients there seems to be a shift of expression; whereas in the crypts the signal appears to be reduced, localization within the surface is increased. The merged localizations within the crypt (blue box) and the surface epithelium (yellow) are also shown in higher magnifications. $\mathrm{Bar}=50 \mathrm{~nm}$.

increase in Cldn-2 expression, but not the decrease of Tric. In contrast, anti-IL13R $\alpha 2$ inhibited the decrease of Tric, but not the Cldn-2 effect (Figure 5a,b). When analyzing the effect on macromolecule permeability using FD4, the inhibition of IL13R $\alpha 1$ by the inhibitory antibody had no suppressing effect on the increase of FD4 permeability after treatment with IL-13. When interaction of IL-13 with the IL13R $\alpha 2$ was inhibited, permeability for FD4 was comparable to untreated cells (Figure 5c). 

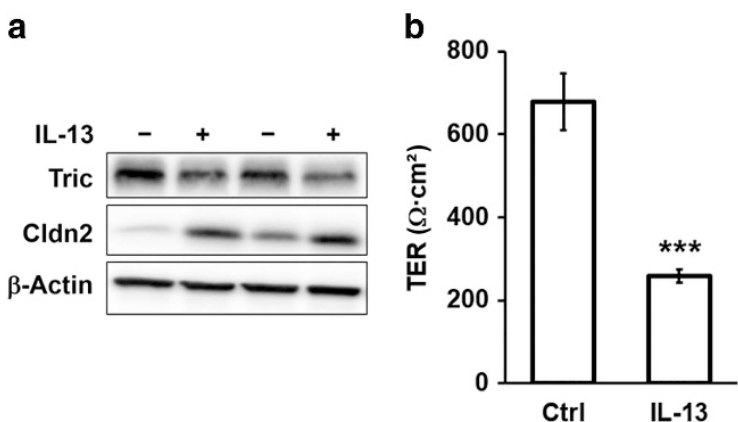

d

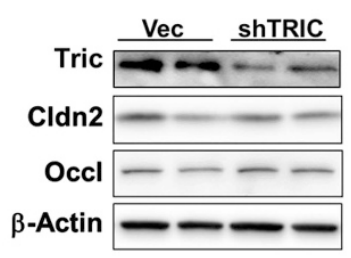

e

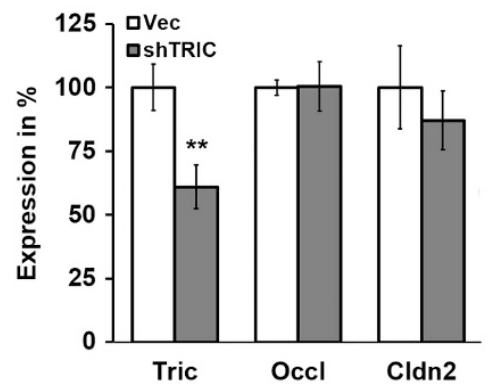

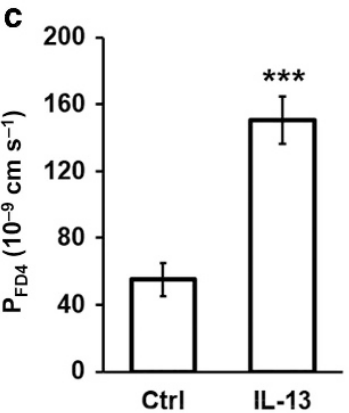

f

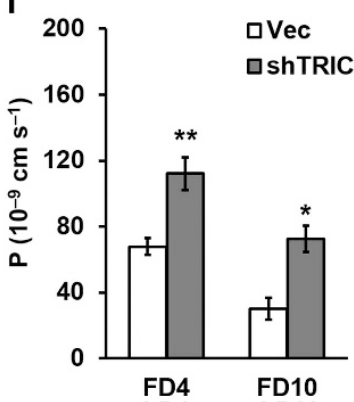

Figure 3 Expression and functional analysis of intestinal cells. (a) Representative western blots. IL-13 treatment lead to decreased tricellulin $\left(72 \pm 4 \%,{ }^{* \star *} P<0.001 ; n=11\right)$ and increased claudin-2 $\left(145 \pm 14 \%,{ }^{* \star} P>0.01 ; n=7\right)$ expression in HT-29/B6 (densitometry Figure 4e). (b) Effect of IL13 on transepithelial resistance. $48 \mathrm{~h}$ incubation with IL-13 decreases $\mathrm{R}^{\mathrm{t}}$ in HT-29/B6 ( $\left.{ }^{\star \star \star} P<0.001\right)$. (c) Effect of IL-13 on permeability for $4 \mathrm{kDa}-\mathrm{FITC}$ dextran (FD4). A total of $48 \mathrm{~h}$ incubation with IL-13 increases permeability to FD4 in HT-29/B6 $\left(^{\star \star \star} P<0.001\right)$ (d) Representative western blots. (e) Densitometric analysis of protein expression levels in stable shTRIC transfectants in comparison to vector-transfected controls. shTRIC leads to decreased tricellulin expression (60 $\left.\pm 9 \%,{ }^{* *} P<0.01, n=10\right)$, but had no influence on expression of claudin-2 $(87 \pm 12 \%, n=5)$ or occludin $($ Occl; $100 \pm 10 \%, n=5$ ). (f) Permeability for the macromolecular paracellular fluxmarkers $4 \mathrm{kDa}$ - and $10 \mathrm{kDa}$-FITC dextran. Both permeabilities are increased in shTRIC clones (FD4: ${ }^{* \star} P<0.01$; FD10: $\left.{ }^{\star} P<0.05\right)$.

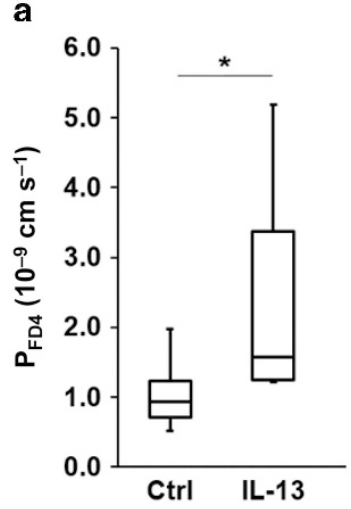

b

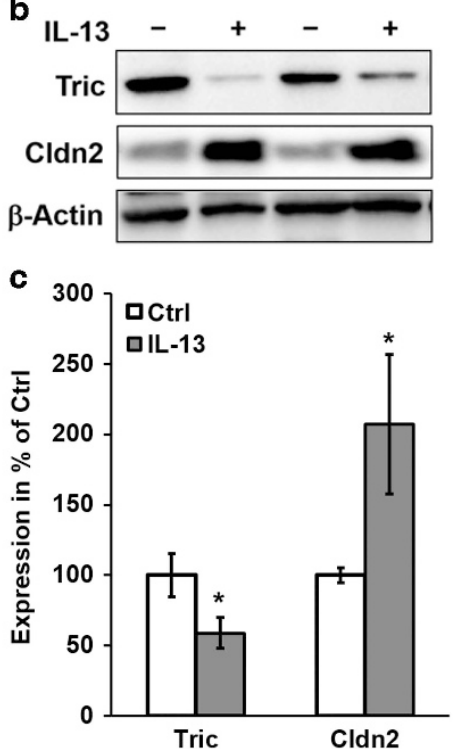

Figure 4 Functional and expression analysis of mice treated with IL-13. (a) Permeability for $4 \mathrm{kDa}-\mathrm{FITC}$ dextran. Permeability for FD4 is increased in mice treated with IL-13 $\left({ }^{*} P<0.05, n=9-12\right)$. (b) Representative western blots. Treatment of mice with IL-13 results in increased claudin-2 and decreased tricellulin expression. (c) Densitometric analysis of protein expression colon tissue of untreated and IL-13-treated mice. After treatment, claudin- 2 is increased and tricellulin is decreased $\left({ }^{\star} P<0.05\right.$, $n=9-12)$.
Also treatment of STAT6 ${ }^{-1-}$ mice with IL-13 reduced Tric expression, indicating that STAT6 and upstream IL13R $\alpha 1$ signaling were not involved (Figure 7a,b). In contrast, Cldn-2 expression was not increased in intestinal mucosae from IL-13-treated STAT6 ${ }^{-1-}$ mice, providing strong data that support for the conclusion from in vitro data ${ }^{33}$ that IL13R $\alpha$ induced STAT6 activation regulates Cldn-2 expression. These differences implicate the IL13R $\alpha 2$ signaling pathway, which is independent of STAT6, to operate in Tric downregulation. Consistent with this, IL-13 in T84 cells, which do not express IL13R $\alpha 2$ (Supplementary Figure S5C), upregulated Cldn2 expression but did not downregulate Tric (Supplementary Figure S5A,B). The same was observed when IL13R $\alpha 2$ was downregulated by stable transfection with specific shRNA (Figure 6a-d). The knockdown of IL13R $\alpha 2$ also abolished the macromolecule permeability increase in response to IL-13 (Figure 6e), supporting the finding of Tric downregulation to be involved in this permeability increase.

To analyze the signal transduction pathway in more detail, several inhibitors known to be regulated by IL-13 ${ }^{28-33,38-41}$ were added before treating the cells with IL-13. For this, protein (Figure 7c, Supplementary Figure S6A) as well as mRNA (Supplementary Figure S6B) levels were analyzed. Cldn-2 upregulation was blocked when IL13R $\alpha 1$-related pathways were inhibited by AS1517499, SAHA (both affecting STAT6), 
a

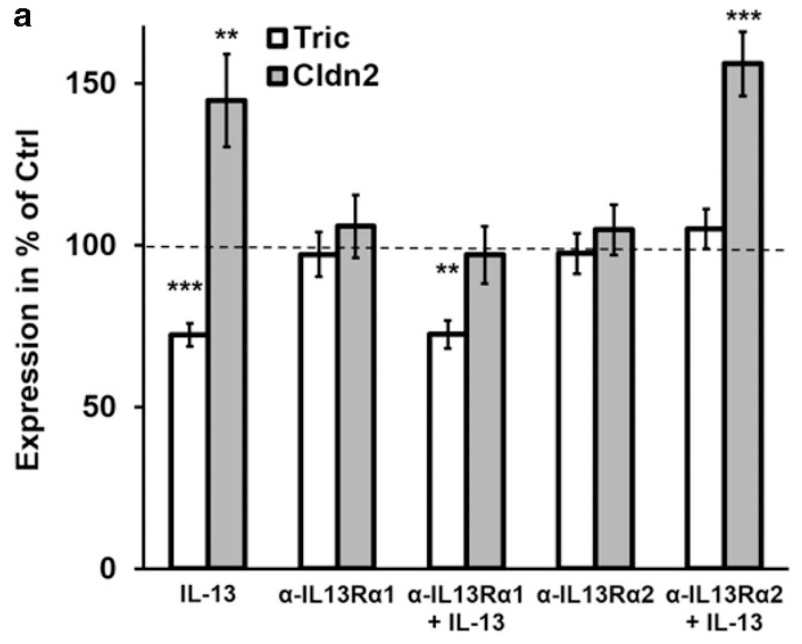

b

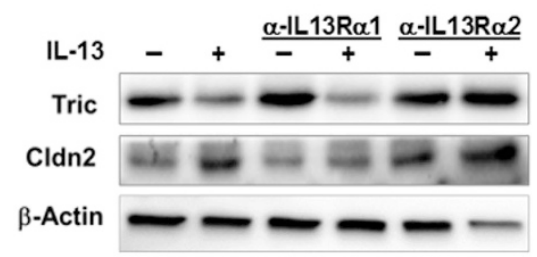

c

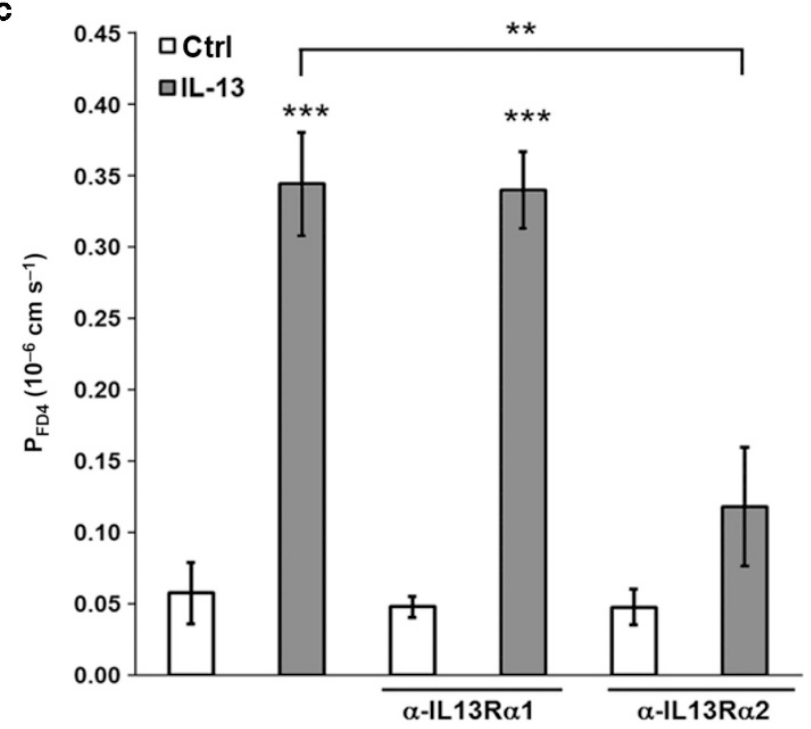

Figure 5 Analysis of the involvement of IL13 receptors in regulation of tricellulin and claudin-2. (a) Densitometric analysis of protein expression of HT-29/B6 cells treated with inhibitory antibodies and IL-13. In HT-29/B6, the inhibitory antibody against IL 13 receptor $\alpha 1$ is able to inhibit the IL-13caused increase of claudin-2, but not the decrease of tricellulin. Tricellulin decrease by IL-13 is inhibited by blocking the IL-13 receptor $\alpha 2$, whereas its inhibition has no effect on the claudin-2 increase $(n=7-11)$. (b) Representative western blots of the incubation with inhibitory antibodies and IL-13. (c) Permeability for 4 kDa-FITC dextran. Permeability for FD4 is increased in HT-29/B6 cells treated with IL-13. This effect was not inhibited by preincubation with the inhibitory antibody against IL 13 receptor $\alpha 1$, but was abolished by preincubation with the inhibitory antibody against IL13 receptor $\alpha 2\left({ }^{\star \star} P<0.01 ;{ }^{\star \star \star} P<0.001, n=4\right)$.

LY294002 (PI3K), or U0126 (MAPK), confirming the findings from the inhibitory antibodies and STAT6 ${ }^{-1-}$ mice. In contrast, downregulation of Tric was inhibited when IL13R $\alpha 2$ pathways were targeted with JNK V, (JNK), U0126 (MAPK,
ERK1/2), or Tanshinone IIa (AP-1). However, not all drugs targeting IL13R $\alpha 2$ signaling prevented Tric downregulation, for example, PI3K. Conversely, JAK1/2 inhibition using baricitinib and JAK3 inhibition using JAK3-inhibitor II had no effect on Cldn-2 expression, although each is thought to be involved in signaling by the IL4R $\alpha / \mathrm{IL} 13 \mathrm{R} \alpha 1$ complex. The data indicate, however, that JAK1 and/or JAK2 are involved in Tric regulation.

To further delineate signaling, expression, and phosphorylation of potential IL13R $\alpha 2$ signaling intermediates were analyzed. To exclude effects being non-specific for Tric, the inhibitor U0126, which was shown to block the Tric downregulation and which is supposed to be involved early in the signaling, was used for comparison (Figure 7d). c-Fos was highly upregulated by IL-13, an effect which was blockable by U0126. All other effects on total protein expression were either not significant or only slightly attenuated by U0126 (Figure 7e). When comparing the phosphorylation status of the respective proteins (Figure 7f), it became obvious that c-Fos phosphorylation was not affected by U0126. However, IL-13 alone markedly decreased c-Fos phosphorylation and increased its total expression. For several other intermediates phosphorylation ratios were increased during IL-13-induced Tric downregulation; IL-13 increased phosphorylation of FRA-1 and of p44/42, an effect that was inhibited when U0126 was present. Interestingly, IL-13 reduced c-jun phosphorylation at S63, and this effect was also inhibited by U0126. Effects of IL-13 on p38 MAPK and p54 SAPK phosphorylation were not inhibited by U0126 and may therefore be unrelated to Tric downregulation.

Tric has been reported as barrier-forming TJ protein inhibiting excessive macromolecule passage through the tTJ. ${ }^{10,11}$ As IL-13 treatment lead to increased FD4 and FD10 permeability, we investigated the site of macromolecule passage through the bTJ and the tTJ of HT-29/B6 monolayers using the recently developed sandwich assay. ${ }^{50}$ In controls, that is, when high amounts of Tric are present, no permeation of biotin-labelled-TRITC-dextran $10 \mathrm{kDa}$ was observed (Figure 8, upper panel, a and b). In contrast, in IL-13-treated cells Tric was reduced and apically added $10 \mathrm{kDa}$ dextran appeared on the basolateral side (Figure 8, lower panel, a and b). In a merged view (Figure 8, lower panel, d), the passage site appeared preferentially at tTJs, in rare cases also at TJs where four cells meet.

When the cells were additionally incubated with the inhibitor Tanshinone IIa, this passage was strongly diminished (Supplementary Figure S7), an effect that we also observed in global analysis of macromolecule permeability performing flux measurements in Ussing chambers (Supplementary Figure S8). IL-4 targeting the complex formed by IL13R $\alpha 1$ and IL4R (Figure 9) had an effect only on Cldn2 but not on Tric expression (Supplementary Figure S1). Consistently, we observed no increased passage of the biotin-labelledTRITC-dextran $10 \mathrm{kDa}$ under these conditions (Supplementary Figure S6).

To demonstrate the localization site of macromolecule passage, representative Z-stack images were rendered into 
a

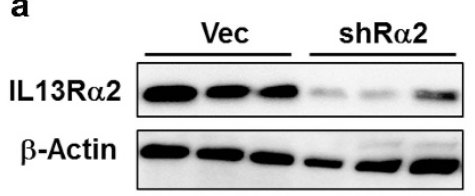

b

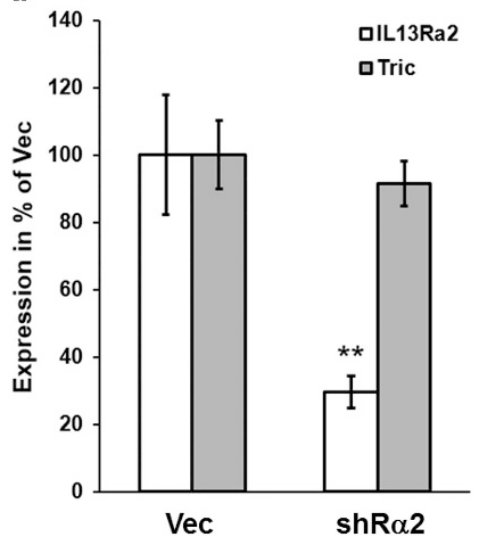

c

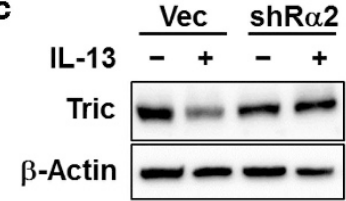

d

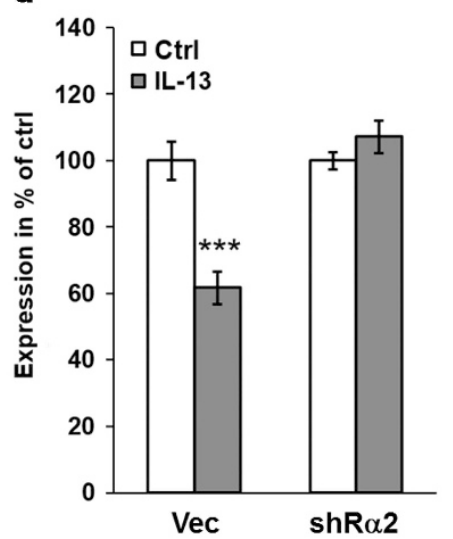

e

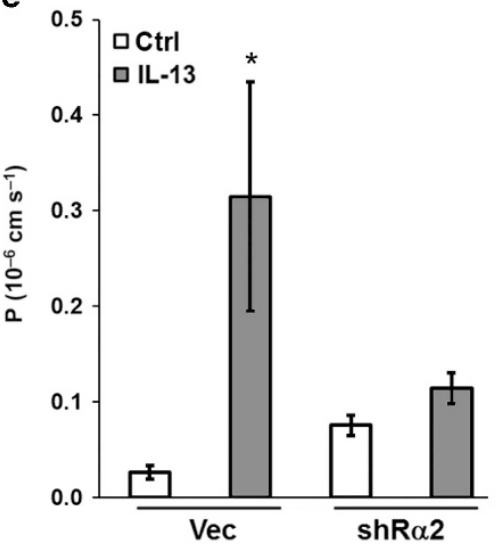

Figure 6 Effects of IL13R $\alpha 2$ knockdown. (a) Representative western blots of different clones of HT-29/B6 cells stably transfected with shRNA against IL $13 R \alpha 2$ (shR $\alpha 2$ ) in comparison with vector-transfected controls. (b) Densitometric analysis of tricellulin and IL13R $\alpha 2$ expression in shR $\alpha 2 \mathrm{knockdown}$ clones $\left(n=4 ;{ }^{* *} P<0.01\right)$. (c) Representative western blots of vector controls and shR $\alpha 2$ clones treated with IL-13. (d) Densitometric analysis of tricellulin expression in shR $\alpha 2$ and vector control clones in response to IL-13-treatment $\left(n=6\right.$; $\left.{ }^{* \star *} P<0.001\right)$. (e) Permeability for $4 \mathrm{kDa}-\mathrm{FITC}$ dextran. Permeability for FD4 is increased in vector controls treated with IL-13, whereas in IL13R $\alpha 2$ knockdown, no effect is observed after IL-13 treatment $(n=8-13$; $\left.{ }^{*} P<0.05\right)$.

three-dimensional movies (Supplementary Movie M1). Comparable observations were made using the shTRIC clone (Supplementary Figure S7 and Supplementary Movie M2), supporting that the macromolecule passage may depend on the level of Tric present in tTJs.

\section{DISCUSSION}

\section{Tric is downregulated in UC, but not in CD}

In this study we analyzed the expression of the $\mathrm{tTJ}$ protein Tric in $\mathrm{CD}$ and UC. Though the intestinal barrier is impaired in both CD and UC, we find Tric to be downregulated only in UC, indicating UC specific downregulation, but not in CD. However, the predominant localization of Tric was shifted toward the surface epithelium in $\mathrm{CD}$, which might indicate that changes in proteins that regulate the correct localization of Tric occur in CD. For example, LSR is known to be predominantly localized within the depths of the crypts, whereas ILDR-1 can be found along the whole crypt. ${ }^{9}$ Thus, regulation of Tric depends also on other tTJ proteins and might be complex in $\mathrm{CD}$, even if total expression remained unchanged. Elucidation of this regulation and involvement of other components of the $\mathrm{tTJ}$ in $\mathrm{CD}$ need to be studied in detail and will be object of further examination.

\section{IL-13 leads to increased paracellular passage of macromolecules via Tric downregulation}

In human biopsies as well as in mice and in HT-29/B6 monolayers, IL-13-induced Tric downregulation resulted in increased macromolecule permeability. Obtaining independent evidence, targeted Tric knockdown had the same effect on macromolecule passage, which is not dependent on occludin or Cldn-2 because both were unchanged. These findings were consistent with previous results from our and other labs. ${ }^{5,10,11,51}$ Our results were corroborated by three-dimensional visualization of macromolecules passing IL-13-treated HT-29/B6 cells predominantly at sites where more than two cells meet.

Taken together, our data demonstrate that the IL-13 induced permeability increase for macromolecules is directly linked to Tric. The mechanistic relation between Tric and opening the passage site for macromolecules is unknown yet and will be the target of future studies.

In conclusion, Tric and the $\mathrm{tTJ}$ are critical to maintenance of the paracellular barrier to macromolecular flux in the intestine. In early stages of UC, Tric downregulation therefore might already destabilize tricellular and TJ tightness, thereby allowing passage of antigens that may further promote the inflammatory process.

\section{IL-13 regulates Cldn-2 and Tric via different signaling pathways}

To elucidate the regulation beyond the decreased Tric expression in UC, we concentrated on IL-13, which is a key cytokine in UC. ${ }^{18}$ Treatment with IL-13 increased Cldn-2 as described earlier ${ }^{18-20}$ and we show here that it also decreased Tric expression. This effect was demonstrated in cell cultures as well as in mice treated with IL-13.

After analyzing the influence of blocking antibodies, knockdown of IL13R $\alpha 2$, inhibitors of reported signaling pathways and mice lacking STAT6, we found that two 
a

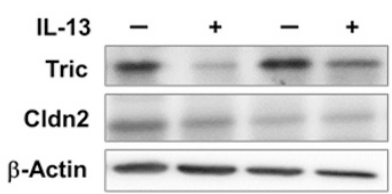

b

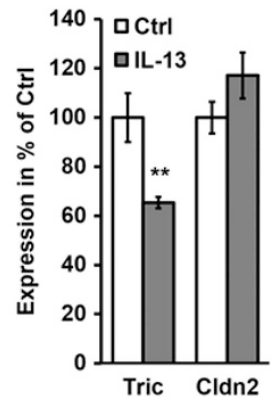

d
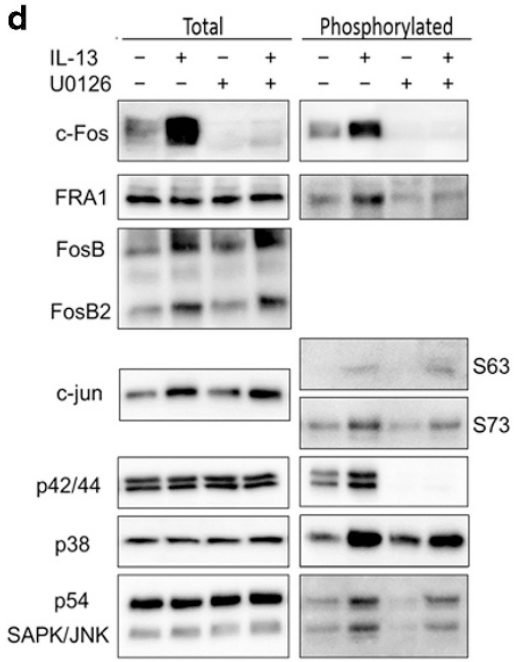

C
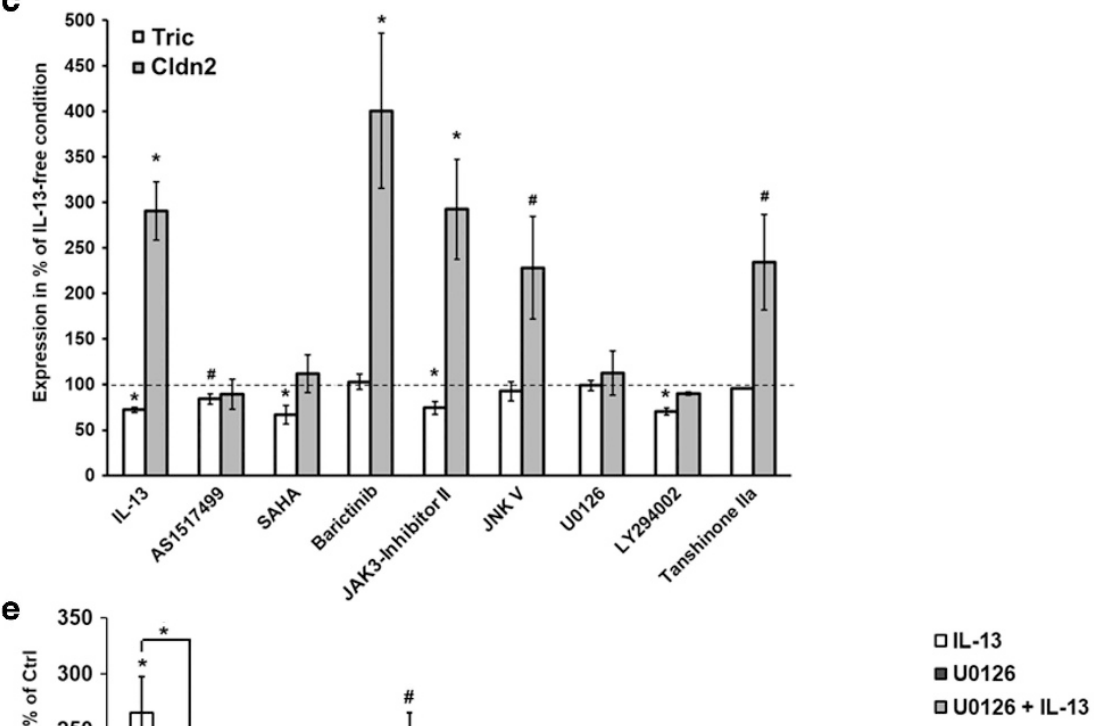

口U $0126+$ IL-13

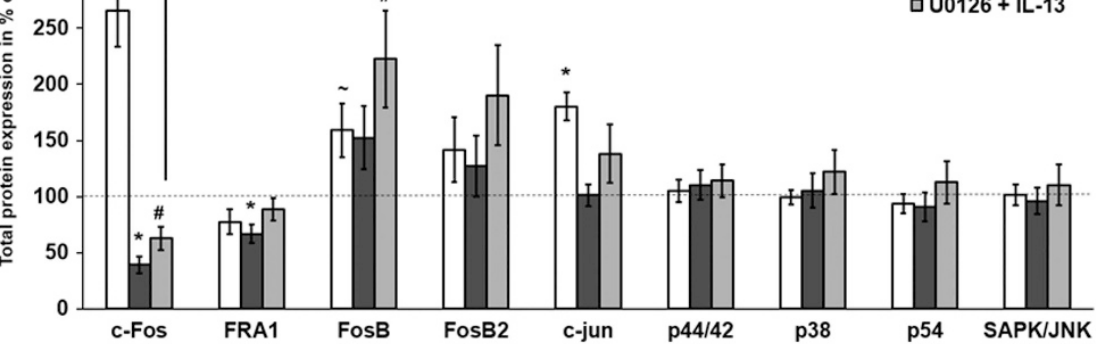

f

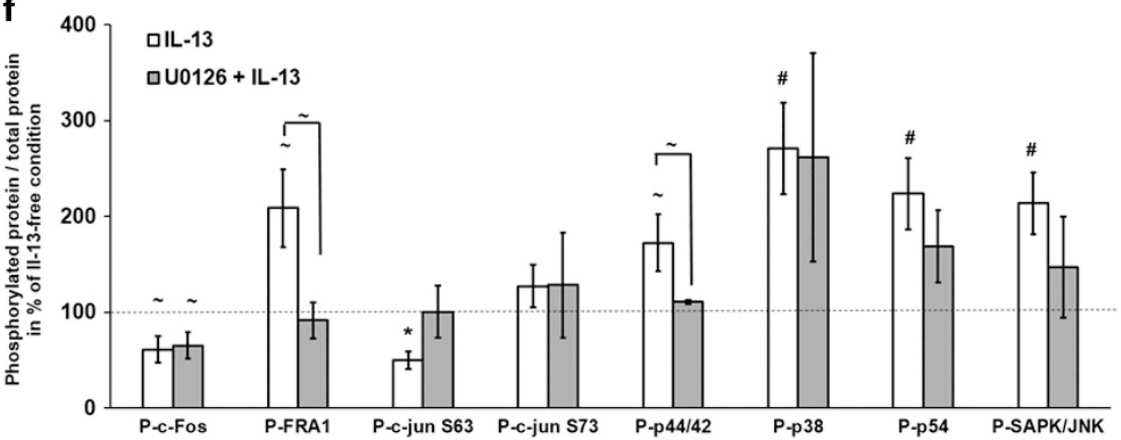

Figure 7 Analysis of the signaling pathways regulating tricellulin and claudin-2. (a) Representative western blots of STAT6 ${ }^{-1-}$ mice treated with IL-13. IL-13 treatment still decreases tricellulin, whereas claudin-2 expression is at levels of untreated mice owing to absence of STAT6 ( $n=4-6)$. (b) Densitometric analysis of protein expression in colon tissue of untreated and IL-13-treated STAT6 ${ }^{-1-}$ mice. After treatment, tricellulin is decreased $\left({ }^{\star *} P<0.01\right)$, whereas claudin-2 is unaffected. (c) Densitometric analysis of protein expression of HT-29/B6 pretreated with different inhibitors before application of IL-13 (representative blots see Supplementary Figure S6, $n=4-12$ ). Protein expression levels were normalized to the respective inhibitor treatment without IL-13. Inhibitors targeting STAT6, ERK1/2, MAPK, and PI3K affect the IL-13-caused increase of claudin-2, whereas inhibitors targeting JAK1 and/or JAK2, JNK, ERK1/2, MAPK, and AP-1 inhibit the IL-13-caused decrease of tricellulin $\left(\# P<0.05 ;{ }^{*} P<0.01, n=6-12\right)$. (d) Representative western blots of total and phosphorylated proteins involved in ERK1/2 and AP-1 signaling. HT-29/B6 cells are either pretreated or not with U0126 before application of IL-13. (e) Densitometric analysis of total protein. Expression of cFos, FosB, and c-jun is increased by IL-13 ( ${ }^{\star} P<0.001$, ${ }^{\#} P<0.01$,

$\sim P<0.05 ; n=12)$. U0126 inhibits this increase for c-Fos (IL-13: $265 \pm 33 \%,{ }^{* * *} P<0.001 ;$ U $0126+I L-13: 63 \pm 11 \%, * * * P<0.001$ to IL-13). (f) Ratio of phosphorylated protein to total protein under influence of IL-13. Phosphorylation levels are increased by IL-13 for FRA-1, p44/42, p38, p54, and SAPK/ JNK and decreased for c-Fos and c-jun (S63; IL-13: $50 \pm 10 \%$, ${ }^{* \star *} P<0.001 ;$ U $0126+\mathrm{IL}-13: 92 \pm 18 \%,{ }^{\star} P<0.05$ to IL-13, $\left.n=12\right)$. These changes in phosphorylation are inhibited by U0126 only for FRA-1 (IL-13: $209 \pm 41 \%,{ }^{*} P<0.05$; U0126 + IL-13: $92 \pm 19 \%,{ }^{\star} P<0.05$ to IL-13, $n=12$ ) and p44/42 (ERK1/2; IL-13: $173 \pm 30 \%,{ }^{\star} P<0.05 ; \mathrm{U} 0126+\mathrm{IL}-13: 6 \pm 2 \%,{ }^{\star} P<0.05$ to IL-13, $\left.n=12\right)(n=10-12)$.

pathways are involved and that each had distinct effects. Based on the established signaling cascades of IL-13 $3^{22-29}$ we conclude that (Figure 9) (i) Cldn-2 expression and trans-TJ pore pathway flux are upregulated via IL-13 binding to the IL4R $\alpha /$ IL13R $\alpha 1$ complex and the subsequent activation of STAT6,
PI3K, and MAPK. (ii) Tric is downregulated and trans-TJ leak pathway flux is enhanced via IL-13 binding to IL13R $\alpha 2$. The subsequent signaling involved ERK1/2, JNK, and AP-1.

The transcription factor AP-1 may be composed of dimers of proteins belonging to the family of Fos, Jun, or ATF proteins. 


\section{ARTICLES}
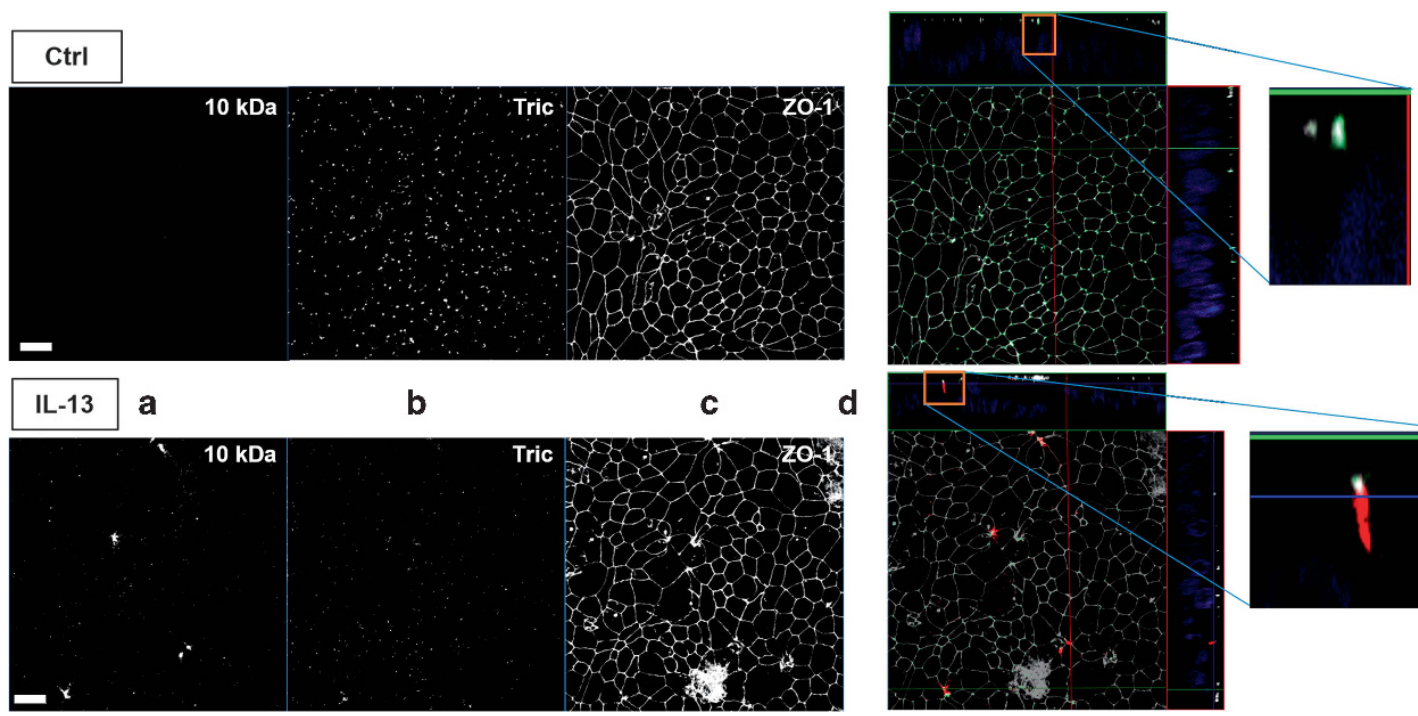

d

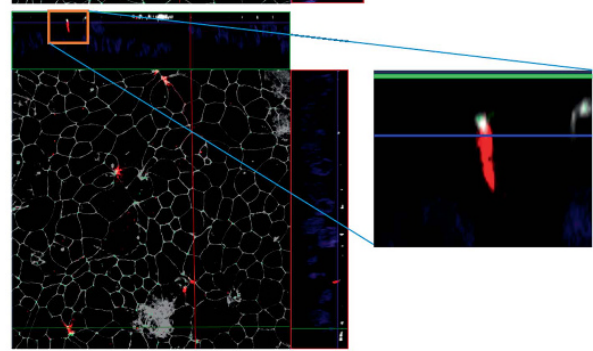

Figure 8 Visualization of macromolecule passage sites by sandwich assay. Maximum intensity projections and Z-stacks of HT-29/B6 immunofluorescence stainings. One out of four experiments is shown here, all yielding the same result. Cells were either untreated (upper panel) or treated with IL-13 (lower panel) and incubated basolaterally with avidin and then apically with biotin- and TRITC-labelled $10 \mathrm{kDa}$-dextran (a). Tricellulin (b) and ZO-1 (c) were counterstained for localization of the macromolecular passage. In merged views featuring Z-stacks and enlarged Z-stacks (d), $10 \mathrm{kDa}$ dextran is shown in red, tricellulin in green, and ZO-1 in gray. IL-13 treatment results in decrease of tricellulin, whereas $10 \mathrm{kDa}$ dextran appears predominantly at sites where more than two cells are in contact. For clearer evaluation of the localization of tricellulin, its signals were increased in contrast, whereas the ZO-1 signals were decreased in d. Bar $=20 \mu \mathrm{m}$.

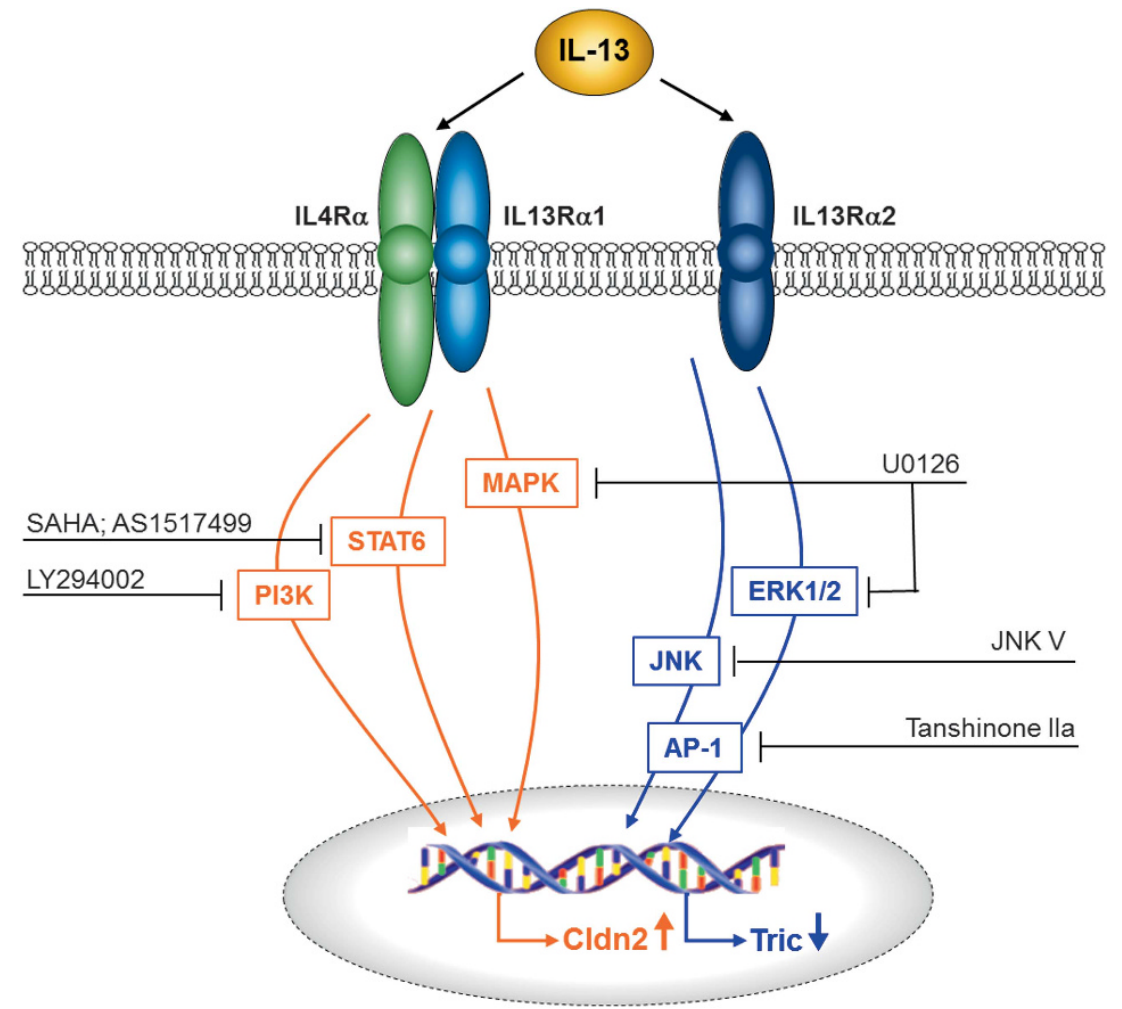

Figure 9 Schematic view of signaling pathways for claudin-2 and tricellulin triggered by IL-13. Although claudin-2 expression is regulated via interaction of IL-13 with the IL4R $\alpha / I L 13 R \alpha 1$ complex, tricellulin expression is regulated via interaction of IL-13 with IL $13 R \alpha 2$ and the downstream signaling cascades.

Analysis of the most common AP-1 sub-proteins revealed that in Tric downregulation by IL-13, higher expression levels of c-Fos as well as the phosphorylation status of FRA-1 and c-jun (position S63) are involved as inhibition by U0126 affected these alterations as well as the Tric decrease.
Taken together, IL-13 affects both, the bTJ and the tTJ. Cldn-2 as size-restrictive channel for small cations and water is a main factor in enhancing the high-capacitive pore-pathway, as by upregulation of Cldn- 2 permeability for $\mathrm{Na}^{+}$increases. This can also be retraced by TER decrease, as TER depends on ions. 
The further influence of IL-13 on the tTJ via downregulation of Tric affects the leak pathway as permeability for macromolecular solutes is increased. However, as in tight epithelia the occurrence of bicellular conductive channels is low (tight epithelia possess a lower paracellular than transcellular conductance), opening of the tTJ also affects ion permeability.

Thus, both effects of IL-13 need to be taken in account when developing new strategies of intervention.

\section{Demand of new receptor-specific IL-13-based intervention strategies}

Our findings indicate that the increased macromolecule passage in UC is at least partly caused by Tric downregulation and that, among all cytokines tested in HT-29/B6 cells, only IL-13 causes Tric downregulation. In contrast, Cldn- 2 expression can be upregulated by several cytokines involved in IBD. The role of Cldn-2 in IBD has been linked to leak flux diarrhea as Cldn-2 increases permeability for small cations as well as for water. On the other hand, recent studies on Cldn-2-overexpressing mice suggested that Cldn-2 also may have protective properties, as these mice were protected against dextran sulfate sodiuminduced colitis. Besides feasible dilution of the dextran sulfate sodium by enhanced paracellular water flux by Cldn-2, it might be speculated whether the additionally described lower immune activation and increased colonocyte proliferation in these mice were leading to the protection. ${ }^{52}$ Increase of Cldn 2 and water flux in IBD might in conclusion have two effects, it may contribute to

\section{Table 1 Cytokine and inhibitor experiments}

\begin{tabular}{lcl}
\hline & Concentration & Source \\
\hline $\begin{array}{c}\text { Cytokine } \\
\text { TNF } \alpha\end{array}$ & \\
IL-4 & $500 \mathrm{U} \mathrm{ml}^{-1}$ & Peprotech, Hamburg, Germany \\
INF $\gamma$ & $100 \mathrm{ng} \mathrm{ml}^{-1}$ & Peprotech, Hamburg, Germany \\
TGF $\beta 1$ & $50 \mathrm{U} \mathrm{ml}^{-1}$ & Peprotech, Hamburg, Germany \\
TGF $\beta 2$ & $10 \mathrm{ng} \mathrm{ml}^{-1}$ & Peprotech, Hamburg, Germany \\
IL-13 & $10 \mathrm{ng} \mathrm{ml}^{-1}$ & Peprotech, Hamburg, Germany \\
& $100 \mathrm{ng} \mathrm{ml}^{-1}$ & Peprotech, Hamburg, Germany
\end{tabular}

\begin{tabular}{|c|c|c|}
\hline SAHA & $5 \mu \mathrm{M}$ & $\begin{array}{l}\text { Sigma-Aldrich, Schnelldorf, } \\
\text { Germany }\end{array}$ \\
\hline Tanshinone lia & $10 \mu \mathrm{M}$ & $\begin{array}{l}\text { Sigma-Aldrich, Schnelldorf, } \\
\text { Germany }\end{array}$ \\
\hline LY294002 & $10 \mu \mathrm{m}$ & $\begin{array}{l}\text { Calbiochem, Darmstadt, } \\
\text { Germany }\end{array}$ \\
\hline JAK3-Inhibitor II & $50 \mu \mathrm{M}$ & $\begin{array}{l}\text { Calbiochem, Darmstadt, } \\
\text { Germany }\end{array}$ \\
\hline JNK V & $10 \mu \mathrm{m}$ & $\begin{array}{l}\text { Calbiochem, Darmstadt, } \\
\text { Germany }\end{array}$ \\
\hline U0126 & $10 \mu \mathrm{M}$ & $\begin{array}{l}\text { Cell Signaling Technology, } \\
\text { Frankfurt am Main, Germany }\end{array}$ \\
\hline AS1517499 & $1 \mu \mathrm{g} \mathrm{ml}^{-1}$ & $\begin{array}{l}\text { Axon Medchem, Groningen, } \\
\text { Netherlands }\end{array}$ \\
\hline Baricitinib & $250 \mathrm{~nm}$ & Selleckchem, Munich, Germany \\
\hline
\end{tabular}

leak-flux diarrhea and by this may serve as a beneficial rinsing of the inflamed mucosa ("enteric tears" 53 ).

IL-13 had been proposed as key player in both UC and asthma, and great hope has been linked to the development of IL-13-focused biologics. However, to date, all approaches have failed: (i) Anrukinzumab, an antibody blocking the attachment of IL-13 to IL $4 \mathrm{R} \alpha$ by binding to IL-13, showed no significant therapeutic effect in active UC, ${ }^{54}$ which is not surprising on the basis of our present data, since the binding to IL13R $\alpha 2$ was unaffected. (ii) A second antibody, tralokinumab which binds and neutralizes IL-13, induced no clinical improvement in UC but at least led to higher clinical remission rates in a subset of patients. $^{55}$ (iii) A third antibody, GSK679586, was directed against the IL-13 binding to both receptors, but was only tested in asthma patients so far. ${ }^{56,57}$

We hypothesize that the earlier attempts to develop biologics targeting IL-13 have failed because they did not differentiate between the two pathways. Targeting solely the IL-13 receptor $\alpha 1$ might be less beneficial or even harmful, because blocking the UC-induced Cldn-2 increase hinders the beneficial rinsing of the inflamed mucosa. In contrast, targeting the IL-13 receptor $\alpha 2$, however, would block the UC-induced decrease of Tric and by this would restore the barrier against the uptake of inflammatory macromolecules. We suggest that inhibiting the IL-13 receptor $\alpha 2$ pathway may be effective in UC, maybe most effective in early stages or in an attempt to achieve remission, when after healing of gross lesions this macromolecule leak is functionally essential. Therefore, new approaches differentiating the two receptors are required for successful treatment.

Not less importantly, Tric itself might be another potential candidate for intervention, targeting the loss of the macromolecular barrier and at the same time uncontrolled luminal uptake of macromolecular agents, especially in early disease states before gross lesions develop.

\section{METHODS}

Patients and tissue preparation. Biopsies from sigmoid colon were obtained from patients with histologically confirmed active UC ( $n=20$, median age of 34 years, range 20-79 years; 9 female and 11 male) or $\mathrm{CD}(n=17$, median age of 38 years, range $21-63$ years; 9 female and 8 male) and from 21 control subjects (Ctrl, median age of 50 years, range $19-75$ years; 14 female and 7 male). Seventeen UC patients received prednisolone (median dose $15 \mathrm{mg}$ per day, range 5-70 mg per day). Of these, nine patients also received 5 -aminosalicylic acid (1.5-5 g per day). Three UC patients only received 5-aminosalicylic acid. Measurements were performed on inflamed specimens without visible erosions/ulcers (histologically mild to moderate inflammation, for example, Supplementary Figure S9). The specimens were spread and glued with histoacryl tissue glue (B Braun, Melsungen, Germany) to a support disk and mounted in Ussing-type chambers with an exposed tissue area of $0.49 \mathrm{~cm}^{2}$. The study design was approved by the local ethics committee (EA4/015/13).

Cell culture and transfections. The human colon cell line HT-29/B6 exhibits a transepithelial resistance and other basic properties making it an excellent model of colonic epithelia. ${ }^{58}$ For stable Tric knockdown, HT-29/B6 cells were transfected with pLKO.1-puro vector containing a sequence for shRNA targeting Tric (TRCN0000072636NM 144724.1-988s1c1TRC 1, Sigma-Aldrich, Schnelldorf, Germany) or targeting IL13R $\alpha 2$ (TRCN0000058526_SHCLNG-NM_000640, 
Sigma-Aldrich) using Amaxa Nucleofector Technology. Puromycinresistant clones were screened for knockdown by western blot. For experimentation, cell monolayers were grown on Millicell-PCF inserts (pore size $3.0 \mu \mathrm{m}$, effective area $0.6 \mathrm{~cm}^{2}$, Millipore, Bedford, MA, USA). Confluent cell layers exhibiting TER above $600 \Omega \mathrm{cm}^{2}$ were used 7 days after seeding.

Cytokine and inhibitor experiments. Cells were incubated as listed in Table 1 for $24 \mathrm{~h}$ (tumor necrosis factor $\alpha$ ) or $48 \mathrm{~h}$ (all others). Treatment with inhibitors occurred $1 \mathrm{~h}$ before IL-13 application. For experiments with inhibitory antibodies, cells were pretreated for $1 \mathrm{~h}$ with $5 \mu \mathrm{g} \mathrm{ml}^{-1}$ mouse anti-CD213a1/IL13Ra1 (AM31180AF-N, Acris, Herford, Germany) or mouse anti-IL13Ra2 (clone 2E10, SigmaAldrich) before addition of IL-13.

Treatment of mice with IL-13. BALB/c wild-type mice (Charité, Forschungseinrichtungen für experimentelle Medizin, Berlin, Germany) and STAT6 ${ }^{-1-}$ mice (Jackson Laboratory, Bar Harbor, MA, USA) were housed, fed, and handled under accordance with the rules of institutional animal care. Experiments were approved by the Landesamt für Gesundheit und Soziales Berlin (G 0208/12). A total of 12-20 week-old female mice were injected intraperitoneally with $3 \mu \mathrm{g}$ murine IL-13 (BioLegend GmbH, Fell, Germany) diluted in $300 \mu \mathrm{l}$ phosphate-buffered saline with $0.1 \%$ bovine serum albumin or vehicle alone daily for three days. $72 \mathrm{~h}$ after the last treatment, mice were killed and colonic tissue was collected for further analysis.

Immunofluorescent staining. Human biopsies and mouse tissue was cryosectioned and fixed with methanol $\left(-20^{\circ} \mathrm{C}\right)$. After permeabilization with $0.5 \%$ Triton-X100 and blocking with $5 \%$ goat serum, sections were incubated with primary antibodies against Cldn-2 (Invitrogen, Karlsruhe, Germany; 1:200) and Tric (Abfinity, Invitrogen; 1:600), followed by washing steps and incubation with the respective secondary antibodies (Alexa Fluor 488 goat anti-mouse and Alexa Fluor 594 goat anti-rabbit, each 1:500; Molecular Probes $\mathrm{MoBiTec}$ ) and 4',6-diamidino-2-phenylindole (1:1000). Images were obtained with a confocal laser scanning microscope (LSM 580, Zeiss).

Electrophysiological and flux measurements. Electrophysiological and flux studies were performed in Ussing chambers under shortcircuit conditions as described earlier. ${ }^{47}$ For flux measurements, after apical addition of fluorescein $(0.1 \mathrm{~mm})$ or FITC-labelled and dialyzed 4 or $10 \mathrm{kDa}$ dextran $(0.4 \mathrm{~mm}$, TdB Consultancy, Sweden) together with basolateral addition of unlabeled dextran of the same size $(0.4 \mathrm{~mm}$, Serva, Heidelberg, Germany), basolateral samples were taken at 0,30 , 60,90 , and $120 \mathrm{~min}$. Tracer fluxes and apparent permeabilities were calculated from the amount of FITC-dextran in the basolateral compartment measured fluorometrically (Tecan Infinite M200, Tecan, Switzerland). One-path impedance analysis was performed employing specialized Ussing chambers as described. ${ }^{59}$

Western blotting, phosphorylation assays, and protein stability. Cells were washed with ice-cold phosphate-buffered saline, scraped from the permeable supports and incubated on ice in lysis buffer containing $10 \mathrm{~mm}$ Tris-Cl (pH 7.5), $150 \mathrm{~mm} \mathrm{NaCl,} \mathrm{0.5 \%} \mathrm{(v/v)} \mathrm{Triton}$ $\mathrm{X}-100,0.1 \%(\mathrm{w} / \mathrm{v})$ sodium dodecyl sulphate, and protease inhibitors (Complete, Roche, Mannheim, Germany). Protein was obtained in the supernatant after a centrifugation at $15,000 \times g\left(15 \mathrm{~min}, 4^{\circ} \mathrm{C}\right)$.

For phosphorylation assays, cells were lysed at one hour after IL-13 treatment using phospholyis buffer $(20 \mathrm{~mm}$ Tris-Cl ( $\mathrm{pH} 7.5)$, $150 \mathrm{~mm} \mathrm{NaCl}, 1 \mathrm{~mm}$ ethylenediaminetetraacetic acid, $1 \mathrm{~mm}$ ethylene glycol tetraacetic acid, $1 \%$ Trition X-100, $2.5 \mathrm{~mm} \mathrm{Na}_{4} \mathrm{P}_{2} \mathrm{O}_{7}, 1 \mathrm{~mm}$ $\beta$-glycerophosphate, $1 \mathrm{~mm} \mathrm{Na} \mathrm{VO}_{4}, 1 \mu \mathrm{g} \mathrm{ml}^{-1}$ leupeptin, $1 \mathrm{~mm}$ phenylmethane sulfonyl fluoride).

For tissues, samples were homogenized in ice-cold lysis buffer $(1 \mathrm{M}$ Tris-Cl pH 7,4, $1 \mathrm{M} \mathrm{MgCl}_{2}, 0.5 \mathrm{M}$ ethylenediaminetetraacetic acid, $0.5 \mathrm{M}$ ethylene glycol tetraacetic acid, protease inhibitors) and pushed through a $1 \mathrm{ml}$ hypodermic syringe with a $0.45 \times 10 \mathrm{~mm}$ needle. Supernatants of a short centrifugation $\left(1,000 \times g, 5 \mathrm{~min}, 4^{\circ} \mathrm{C}\right)$ were centrifuged $\left(42,100 \times g, 30 \mathrm{~min}, 4^{\circ} \mathrm{C}\right)$ and the resulting pellets containing the membrane protein fraction were resolved in lysis buffer.

A total of $10 \mu \mathrm{g}$ of the protein samples were electrophoresed on a sodium dodecyl sulphate-polyacrylamide gel and then transferred to a PVDF membrane (Perkin Elmer, Rodgau, Germany). Proteins were detected by immunoblotting employing primary antibodies against Cldn-2 and -4 (Invitrogen), Tric (Abfinity, Invitrogen), c-Fos, phopsho-c-Fos, c-jun, phospho-c-junS63, phospho-c-junS73, FRA1, phospho-FRA1, SAPK/JNK, phospho-SAPK/JNK, ERK1/2, phospho-ERK1/2, p38 and phospho-p38 (Cell Signaling Technology). For chemiluminescence detection, membranes were washed and incubated with Lumi-Light ${ }^{\text {plus }}$ (Roche). Specific signals were quantified by luminescence imaging (Fusion FX7, Vilber Lourmat, Eberhardzell, Germany) and quantification software (Multi Gauge V2.3, FujiFilm, Japan).

For analysis of protein stability, HT-29/B6 cells were cultured in the presence or absence of IL-13, whereas protein synthesis was blocked by addition of $100 \mu \mathrm{g} \mathrm{ml}^{-1}$ cycloheximide (Sigma-Aldrich) $2 \mathrm{~h}$ prior to cytokine treatment. Protein was isolated $0,2,8,12,24,30$, and $48 \mathrm{~h}$ after IL-13 addition, and Tric protein expression was evaluated by western blotting. Amounts of Tric were plotted against time on a logarithmic scale. The half-life $\left(\mathrm{T}_{1 / 2}\right)$ of the protein was calculated from the slope of the linear smoothing function.

Isolation of RNA, reverse transcription, qRT-PCR, and mRNA stability. RNA was isolated using the peqGOLD RNAPure (peqLab Biotechnologie GmbH, Erlangen, Germany) according to the manufacturer's instructions and RNA was quantified by NanoDrop ND1000 UV-Vis Spectrophotometer (peqLab Biotechnologie GmbH).

A total of $2 \mu \mathrm{g}$ of total RNA per reaction were reverse-transcribed using High Capacity cDNA Reverse Transcription Kit (Applied Biosystems, Mannheim, Germany). Quantitative RT-PCR of Tric (Hs00930631_m1), Cldn-2 (Hs00252666_s1) and glyceraldehyde 3-phosphate dehydrogenase as control were amplified using taqman probes (Applied Biosystems). Differential expression was calculated according to the $2^{-\triangle \Delta \mathrm{CT}}$ method.

For analysis of mRNA stability, HT-29/B6 cells were cultured in the presence or absence of IL-13, whereas RNA transcription $1 \mathrm{~h}$ in advance was blocked by addition of $7 \mu \mathrm{g} \mathrm{ml}^{-1}$ actinomycin D (SigmaAldrich). RNA was isolated $0,6,12,24$, and $28 \mathrm{~h}$ after actinomycin D addition, reversely transcribed, and quantified by RT-PCR. Amounts of the target-specific copies were plotted against time on a logarithmic scale and the half-life $\left(\mathrm{T}_{1 / 2}\right)$ of mRNA was calculated.

TUNEL staining. Cells were fixed in 1\% paraformaldehyde and DNA was stained with a TUNEL assay (TdT-mediated X-dUTP nick end labeling; Roche). Labeled nuclei were counted and expressed as a fraction of total 4',6-diamidino-2-phenylindole-stained nuclei.

Passage visualization. For visualization of macromolecule passage, the recently developed sandwich assa ${ }^{50}$ was slightly modified. In brief, filter supports (pore size $0.45 \mu \mathrm{m}$ ) were transferred to chilled HEPESbuffered ringer, kept at $4{ }^{\circ} \mathrm{C}$ and basally incubated with $15 \mu \mathrm{M}$ avidin (Lee Biosolutions, MO) for $20 \mathrm{~min}$. Excess avidin was removed by washing. $10 \mu \mathrm{M}$ biotin-labelled TMR-dextran $10 \mathrm{kDa}$ (Invitrogen) was added apically for $1 \mathrm{~h}$ and then carefully removed by washing. Cells were fixed with 2\% paraformaldehyde (Electron Microscopy Sciences, Maryland Heights, MO) and used for subsequent immunofluorescent staining of ZO-1 (BD, Heidelberg, Germany) and Tric (Abfinity, Invitrogen).

Statistical analysis. If not differently stated, data are expressed as mean values \pm s.e.m. indicating $n$ as the number of single, independent measurements. Statistical analysis was performed using Student's $t$-test with Bonferroni-Holm adjustment for multiple testing or the MannWhitney-test for not normally distributed data. $P<0.05$ was considered significant $\left({ }^{\star} P<0.05,{ }^{* *} P<0.01,{ }^{* *} P<0.001\right)$.

SUPPLEMENTARY MATERIAL is linked to the online version of the paper at http://www.nature.com/mi 


\section{ACKNOWLEDGMENTS}

This study was supported by grants from the Deutsche Forschungsgemeinschaft (DFG FOR 721/2, KR 3807/1-1, Schu 559/11-2), from the Sonnenfeld-Stiftung Berlin, and from the US National Institutes of Health (DK061931).

\section{AUTHOR CONTRIBUTIONS}

Design of work: SMK, MF, JRT, JDS.

Data aquiration: SMK, CB, AF, IML. PD.

Result interpretation: SMK, JFR, JRT,MF, JDS.

Drafting of manuscript: SMK, MF.

Revision of manuscript: CB, AF, IML, PD, JFR, JRT, MF, JDS.

Appoval of final version: SMK, CB, AF, IML, PD, JFR, MF, JDS.

\section{DISCLOSURE}

The authors declare no conflict of interest.

c) 2018 Society for Mucosal Immunology

\section{REFERENCES}

1. Mineta, K. et al. Predicted expansion of the claudin multigene family. FEBS Lett. 585, 606-612 (2011).

2. Raleigh, D.R. et al. Tight junction-associated MARVEL proteins marveld3, tricellulin, and occludin have distinct but overlapping functions. Mol. Biol. Cell. 21, 1200-1213 (2010).

3. Furuse, M. et al. Occludin: a novel integral membrane protein localizing at tight junctions. J. Cell Biol. 123, 1777-1788 (1993).

4. Steed, E., Rodrigues, N.T., Balda, M.S. \& Matter, K. Identification of MarvelD3 as a tight junction-associated transmembrane protein of the occludin family. BMC Cell Biol. 10, 95 (2009).

5. Ikenouchi, J., Furuse, M., Furuse, K., Sasaki, H., Tsukita, S. \& Tsukita, S. Tricellulin constitutes a novel barrier at tricellular contacts of epithelial cells. J. Cell Biol. 171, 939-945 (2005).

6. Colegio, O.R., Van Itallie, C.M., McCrea, H.J., Rahner, C. \& Anderson, J.M. Claudins create charge-selective channels in the paracellular pathway between epithelial cells. Am. J. Physiol. Cell Physiol. 283, C142-C147 (2002).

7. Krug, S.M., Schulzke, J.D. \& Fromm, M. Tight junction, selective permeability, and related diseases. Semin. Cell Dev. Biol. 36, 166-176 (2014).

8. Ebnet, K., Suzuki, A., Ohno, S. \& Vestweber, D. Junctional adhesion molecules (JAMs): more molecules with dual functions?. J. Cell Sci. 117, 19-29 (2004).

9. Higashi, T. et al. Analysis of the 'angulin' proteins LSR, ILDR1 and ILDR2-tricellulin recruitment, epithelial barrier function and implication in deafness pathogenesis. J. Cell Sci. 126, 966-977 (2013).

10. Krug, S.M., Amasheh, M., Dittmann, I., Christoffel, I., Fromm, M. \& Amasheh, S. Sodium caprate as an enhancer of macromolecule permeation across tricellular tight junctions of intestinal cells. Biomaterials 34, 275-282 (2013).

11. Krug, S.M. et al. Tricellulin forms a barrier to macromolecules in tricellular tight junctions without affecting ion permeability. Mol. Biol. Cell 20, 3713-3724 (2009).

12. Baumgart, D.C. \& Sandborn, W.J. Crohn's disease. Lancet 380, 1590-1605 (2012).

13. Ordas, I., Eckmann, L., Talamini, M., Baumgart, D.C. \& Sandborn, W.J. Ulcerative colitis. Lancet 380, 1606-1619 (2012).

14. Scharl, M. \& Rogler, G. Inflammatory bowel disease pathogenesis: what is new? Curr. Opin. Gastroenterol. 28, 301-309 (2012).

15. Chen, P., Li, J., Barnes, J., Kokkonen, G.C., Lee, J.C. \& Liu, Y. Restraint of proinflammatory cytokine biosynthesis by mitogen-activated protein kinase phosphatase-1 in lipopolysaccharide-stimulated macrophages. J. Immunol. 169, 6408-6416 (2002).

16. Bruewer, M. et al. Proinflammatory cytokines disrupt epithelial barrier function by apoptosis-independent mechanisms. J. Immunol. 171, 6164-6172 (2003).

17. Wang, F., Graham, W.V., Wang, Y., Witkowski, E.D., Schwarz, B.T. \& Turner, J.R. Interferon-gamma and tumor necrosis factor-alpha synergize to induce intestinal epithelial barrier dysfunction by up-regulating myosin light chain kinase expression. Am. J. Pathol. 166, 409-419 (2005).

18. Heller, F. et al. Interleukin-13 is the key effector Th2 cytokine in ulcerative colitis that affects epithelial tight junctions, apoptosis, and cell restitution. Gastroenterology 129, 550-564 (2005).

19. Weber, C.R. et al. Epithelial myosin light chain kinase activation induces mucosal interleukin-13 expression to alter tight junction ion selectivity. J. Biol. Chem. 285, 12037-12046 (2010).

20. Heller, F., Fromm, A., Gitter, A.H., Mankertz, J. \& Schulzke, J.D. Epithelial apoptosis is a prominent feature of the epithelial barrier disturbance in intestinal inflammation: effect of pro-inflammatory interleukin-13 on epithelial cell function. Mucosal Immunol. 1, S58-S61 (2008).

21. Miossec, P. \& van den Berg, W. Th1/Th2 cytokine balance in arthritis. Arthritis Rheum. 40, 2105-2115 (1997).

22. David, M., Ford, D., Bertoglio, J., Maizel, A.L. \& Pierre, J. Induction of the $\mathrm{IL}-13$ receptor alpha2-chain by $\mathrm{IL}-4$ and IL-13 in human keratinocytes: involvement of STAT6, ERK and p38 MAPK pathways. Oncogene 20, 6660-6668 (2001).

23. Donaldson, D.D. et al. The murine IL-13 receptor alpha 2: molecular cloning, characterization, and comparison with murine $\mathrm{IL}-13$ receptor alpha 1. J. Immunol 161, 2317-2324 (1998).

24. Mandal, D., Fu, P. \& Levine, A.D. REDOX regulation of IL-13 signaling in intestinal epithelial cells: usage of alternate pathways mediates distinct gene expression patterns. Cell. Signal. 22, 1485-1494 (2010).

25. Wood, N. et al. Enhanced interleukin (IL)-13 responses in mice lacking IL-13 receptor alpha 2. J. Exp. Med. 197, 703-709 (2003).

26. Hershey, G.K. IL-13 receptors and signaling pathways: an evolving web. J. Allergy Clin. Immunol 111, 677-690 (2003).

27. Kelly-Welch, A.E., Hanson, E.M., Boothby, M.R. \& Keegan, A.D. Interleukin-4 and interleukin-13 signaling connections maps. Science 300, 1527-1528 (2003).

28. Roy, B., Bhattacharjee, A., Xu, B., Ford, D., Maizel, A.L. \& Cathcart, M.K. IL-13 signal transduction in human monocytes: phosphorylation of receptor components, association with Jaks, and phosphorylation/ activation of Stats. J. Leukoc. Biol 72, 580-589 (2002).

29. Murata, T., Husain, S.R., Mohri, H. \& Puri, R.K. Two different IL-13 receptor chains are expressed in normal human skin fibroblasts, and IL-4 and IL-13 mediate signal transduction through a common pathway. Int. Immunol 10 1103-1110 (1998).

30. Atherton, H.C., Jones, G. \& Danahay, H. IL-13-induced changes in the goblet cell density of human bronchial epithelial cell cultures: MAP kinase and phosphatidylinositol 3-kinase regulation. Am. J. Physiol. Lung Cell. Mol. Physiol. 285, L730-L739 (2003).

31. Iwashita, J., Sato, Y., Sugaya, H., Takahashi, N., Sasaki, H. \& Abe, T. mRNA of MUC2 is stimulated by $\mathrm{LL}-4, \mathrm{LL}-13$ or TNF-alpha through a mitogenactivated protein kinase pathway in human colon cancer cells. Immunol. Cell Biol. 81, 275-282 (2003).

32. Wright, K., Kolios, G., Westwick, J. \& Ward, S.G. Cytokine-induced apoptosis in epithelial HT-29 cells is independent of nitric oxide formation. Evidence for an interleukin-13-driven phosphatidylinositol 3-kinase-dependent survival mechanism. J. Biol. Chem. 274, 17193-17201 (1999).

33. Rosen, M.J. et al. STAT6 activation in ulcerative colitis: a new target for prevention of IL-13-induced colon epithelial cell dysfunction. Inflamm. Bowel Dis. 17, 2224-2234 (2011).

34. Zhang, J.G. et al. Identification, purification, and characterization of a soluble interleukin (IL)-13-binding protein. Evidence that it is distinct from the cloned II-13 receptor and II-4 receptor alpha-chains. J. Biol. Chem. 272, 9474-9480 (1997).

35. Daines, M.O. et al. Level of expression of $I \mathrm{~L}-13 \mathrm{R}$ alpha 2 impacts receptor distribution and IL-13 signaling. J. Immunol. 176, 7495-7501 (2006).

36. Chen, W. et al. IL-13R alpha 2 membrane and soluble isoforms differ in humans and mice. J. Immunol. 183, 7870-7876 (2009).

37. Mentink-Kane, M.M. et al. IL-13 receptor alpha 2 down-modulates granulomatous inflammation and prolongs host survival in schistosomiasis. Proc. Natl. Acad. Sci. USA 101, 586-590 (2004).

38. Fichtner-Feigl, S., Strober, W., Kawakami, K., Puri, R.K. \& Kitani, A. IL-13 signaling through the IL-13alpha2 receptor is involved in induction of TGF-beta1 production and fibrosis. Nat. Med. 12, 99-106 (2006). 
39. Fujisawa, T., Joshi, B.H. \& Puri, R.K. IL-13 regulates cancer invasion and metastasis through IL-13Ralpha2 via ERK/AP-1 pathway in mouse model of human ovarian cancer. Int. J. Cancer 131, 344-356 (2012).

40. Rahaman, S.O., Vogelbaum, M.A. \& Haque, S.J. Aberrant Stat3 signaling by interleukin-4 in malignant glioma cells: involvement of IL-13Ralpha2. Cancer Res. 65, 2956-2963 (2005).

41. Barderas, R., Bartolome, R.A., Fernandez-Acenero, M.J., Torres, S. \& Casal, J.I. High expression of IL-13 receptor alpha2 in colorectal cancer is associated with invasion, liver metastasis, and poor prognosis. Cancer Res. 72, 2780-2790 (2012).

42. Zeissig, S. et al. Downregulation of epithelial apoptosis and barrier repair in active Crohn's disease by tumour necrosis factor alpha antibody treatment. Gut 53, 1295-1302 (2004).

43. Oshima, T., Miwa, H. \& Joh, T. Changes in the expression of claudins in active ulcerative colitis. J. Gastroenterol. Hepatol. 23, S146-S150 (2008).

44. Olsen, J. et al. Diagnosis of ulcerative colitis before onset of inflammation by multivariate modeling of genome-wide gene expression data. Inflamm. Bowel Dis. 15, 1032-1038 (2009).

45. Edgar, R., Domrachev, M. \& Lash, A.E. Gene Expression Omnibus: NCBI gene expression and hybridization array data repository. Nucleic Acids Res. 30, 207-210 (2002).

46. Moehle, C. et al. Aberrant intestinal expression and allelic variants of mucin genes associated with inflammatory bowel disease. J. Mol. Med 84, 10551066 (2006).

47. Zeissig, S. et al. Changes in expression and distribution of claudin 2, 5 and 8 lead to discontinuous tight junctions and barrier dysfunction in active Crohn's disease. Gut 56, 61-72 (2007).

48. Dames, P. et al. Interleukin-13 affects the epithelial sodium channel in the intestine by coordinated modulation of STAT6 and p38 MAPK activity. J. Physiol. 593, 5269-5282 (2015).

49. Turner, J.R. Intestinal mucosal barrier function in health and disease. Nat. Rev. Immunol. 9, 799-809 (2009).
50. Richter, J.F., Schmauder, R., Krug, S.M., Gebert, A. \& Schumann, M. A novel method for imaging sites of paracellular passage of macromolecules in epithelial sheets. J. Control. Release 229, 70-79 (2016).

51. Kolosov, D. \& Kelly, S.P. A role for tricellulin in the regulation of gill epithelium permeability. Am J. Physiol. Regul. Integr. Compar. Physiol. 304, R1139-R1148 (2016).

52. Ahmad, R. et al. Targeted colonic claudin-2 expression renders resistance to epithelial injury, induces immune suppression, and protects from colitis. Mucosal Immunol. 7, 1340-1353 (2014).

53. Keely, S., Feighery, L., Campion, D.P., O’Brien, L., Brayden, D.J. \& Baird, A.W. Chloride-led disruption of the intestinal mucous layer impedes Salmonella invasion: evidence for an 'enteric tear' mechanism. Cell. Physiol. Biochem. 28, 743-752 (2011).

54. Reinisch, W. et al. Anrukinzumab, an anti-interleukin 13 monoclonal antibody, in active UC: efficacy and safety from a phase lla randomised multicentre study. Gut 64, 894-900 (2015).

55. Danese, S. et al. Tralokinumab for moderate-to-severe UC: a randomised, double-blind, placebo-controlled, phase lla study. Gut 64, 243-249 (2015).

56. De Boever, E.H. et al. Efficacy and safety of an anti-IL-13 mAb in patients with severe asthma: a randomized trial. J. Allergy Clin. Immunol 133, 989-996 (2014).

57. Hodsman, P. et al. A phase 1, randomized, placebo-controlled, dose-escalation study of an anti-IL-13 monoclonal antibody in healthy subjects and mild asthmatics. Br. J. Clin. Pharmacol. 75, 118128 (2013).

58. Kreusel, K.M., Fromm, M., Schulzke, J.D. \& Hegel, U. Cl- secretion in epithelial monolayers of mucus-forming human colon cells (HT-29/B6). Am. J. Physiol. 261, C574-C582 (1991).

59. Stockmann, M., Gitter, A.H., Sorgenfrei, D., Fromm, M. \& Schulzke, J.D. Low edge damage container insert that adjusts intestinal forceps biopsies into Ussing chamber systems. Pflugers Arch. 438, 107-112 (1999). 